\title{
Laboratory test ordering in inpatient hospitals: a systematic review on the effects and features of clinical decision support systems
}

Sahar Zare ${ }^{1}$, Zahra Meidani ${ }^{1,2}$, Mohammad Shirdeli $^{3}$ and Ehsan Nabovati, ${ }^{1 *}$ (D)

\begin{abstract}
Background: Studies have revealed inappropriate laboratory testing as a source of waste. This review aimed at evaluating the effects and features of CDSSs on physicians' appropriate laboratory test ordering in inpatient hospitals.

Method: Medline through PubMed, SCOPUS, Web of Science, and Cochrane were queried without any time period restriction. Studies using CDSSs as an intervention to improve laboratory test ordering as the primary aim were included. The study populations in the included studies were laboratory tests, physicians ordering laboratory tests, or the patients for whom laboratory tests were ordered. The included papers were evaluated for their outcomes related to the effect of CDSSs which were categorized based on the outcomes related to tests, physician, and patients. The primary outcome measures were the number and cost of the ordered laboratory tests. The instrument from The National Heart Lung and Blood Institute $(\mathrm{NIH})$ was used to assess the quality of the included studies. Moreover, we applied a checklist for assessing the quality and features of the CDSSs presented in the included studies. A narrative synthesis was used to describe and compare the designs and the results of included studies.
\end{abstract}

Result: Sixteen studies met the inclusion criteria. Most studies were conducted based on a quasi-experimental design. The results showed improvement in laboratory test-related outcomes (e.g. proportion and cost of tests) and also physician-related outcomes (e.g. guideline adherence and orders cancellation). Patient-related outcomes (e.g. length of stay and mortality rate) were not well investigated in the included studies. In addition, the evidence about applying CDSS as a decision aid for interpreting laboratory results was rare.

Conclusion: CDSSs increase appropriate test ordering in hospitals through eliminating redundant test orders and enhancing evidence-based practice. Appropriate testing and cost saving were both affected by the CDSSs. However, the evidence is limited about the effects of laboratory test CDSSs on patient-related outcomes.

Keywords: Clinical decision support system, Test ordering, Hospitals, Laboratories, Inpatients

\section{Background}

The results of laboratory tests have an important impact on patients' care, as they influence physicians' decisions including admission, drug orders, and discharge as well as

\footnotetext{
*Correspondence: enabovati@gmail.com

1 Health Information Management Research Center (HIMRC), 5th

of Qotb -e Ravandi Blvd, Kashan University of Medical Science,

87159-73449 Kashan, Iran

Full list of author information is available at the end of the article
}

monitoring and managing the vast majority of diseases. However, studies indicate that diagnostic tests are being used inappropriately as a meta-analysis result showed that almost $20 \%$ of laboratory tests are over-utilized and $45 \%$ are under-utilized [1]. A study has indicated that only $1-5 \%$ of chemistry tests and $1-3 \%$ of hematology tests have led to an action; action in this study meant any alternation from what would have been done without the test result [2]. Moreover, about $70 \%$ of residents, in one 
study were reported that they were ordering unnecessary daily laboratory tests [3].

Inappropriate test ordering can increase the risk of false positive results as well as medical errors [4]. Overutilization can potentially cause patient discomfort including phlebotomy-induced anemia [5]. Underutilization can also result in delayed or missed diagnosis. Studies have found that a vast majority of claims both in outpatients and emergency department belongs to missed diagnosis resulting in death or serious harm to patients $[6,7]$. Overcrowded diagnostic services, increased length of stay (LOS), and waste of valuable healthcare resources are amongst other consequences of inappropriate testing [8-10]. Conversely, it imposes a lot of costs to healthcare as $3 \%$ of health care expenditures in the USA belong to laboratory testing [11-13].

Information technology [IT] has provided some solutions to decrease inappropriate laboratory tests ordering. Some of these technologies are electronic medical record (EMR) [14], electronic health record (EHR) [15], computerized physician order entry (CPOE) [16], and clinical decision support systems (CDSS) [17]. Of all these, CDSS has more potential to support physicians when deciding about ordering a test or interpreting the results. However, studies have shown inconsistent results about the impact of CDSSs on physicians' performance and patients outcomes $[18,19]$. Thus, there is a need for a scoping review on the effects of CDSSs on ordering appropriate laboratory tests.

Studies evaluating the impact of CDSSs on diagnostic testing showed no improvement in clinical outcome but small positive improvement on physicians behavior regarding diagnostic test ordering $[20,21]$. There are two similar systematic reviews focusing on laboratory test ordering specifically. The first is Maillet et al. study [22] which addressed the IT impact on laboratory tests ordering process in primary healthcare. This study did not focus on the effectiveness of CDSSs rather it focused on some specific IT interventions. It also included the studies conducted in primary healthcare. The second systematic review by Delvaux et al. [23] included the studies conducted in diverse healthcare settings (i.e. primary healthcare, hospital outpatient, and hospital inpatient). They found that CDSSs had little or no effect on clinical outcomes but some effects on physician compliance rate. Neither of the studies has investigated the features of the included CDSSs mentioned as a suggestion in Delvaux et al. study [23]. Taking into account all studies conducted in inpatient hospitals and aimed at improving laboratory testing process, without considering study designs, might produce different results. Furthermore, features of successful CDSSs need to be investigated. Thus, the goal of current study was to conduct a systematic review on the effects and features of CDSSs on physicians' appropriate laboratory tests ordering in inpatient hospitals.

\section{Method \\ Research question}

Do CCDSSs improve practitioners' appropriate laboratory test ordering in hospitals?

\section{Search strategy and study selection}

A search strategy was developed using keywords, $\mathrm{MeSH}$ terms, and major subject headings to identify published papers in the literature and adaptations were made for each database. Four databases were queried: Medline (through PubMed), SCOPUS, Web of Science, and Cochrane. We considered studies published till 21 January 2020 without any time limitation. The search strategy consisted of a combination of keywords and Mesh terms related to clinical laboratory services (laboratory test utilization), CDSSs, and hospitals. The search strategy is presented as supplementary (Additional file 1: supplementary A).

After removing duplicates, two authors (SZ and MS), working independently, selected the papers based on eligibility criteria. Titles and abstracts were screened for inclusion. The full text of potentially relevant papers was obtained, and both inclusion and exclusion criteria were considered. The reference lists of the identified papers were also searched to include any other paper missed during the electronic searches. Authors resolved disagreements through discussion and consensus, and any remaining disagreements were resolved by another author (EN).

\section{Study selection criteria Inclusion criteria}

Type of studies A variety of evaluation study designs were included: randomized controlled trials (RCTs), nonrandomized controlled clinical trials (CCTs), prospective observational studies, before-after, and interrupted time series (ITS).

Type of population The study populations in the included studies were laboratory tests, physicians ordering laboratory tests, or the patients for whom laboratory tests were ordered.

Types of interventions Studies using CDSSs as an intervention to improve laboratory test ordering as the primary aim were included. In current study, a CDSS is considered as a health information technology system designed to provide assistance to physicians at the time of decisionmaking. CDSSs can facilitate access to data which are required to make decisions, provide reminders while a 
patient encounters, assists in both recognizing a diagnosis and entering appropriate orders, and alerts healthcare providers when new patterns in patient data are observed $[22,24]$. In studies with multifaceted interventions, the effects of CDSS intervention were considered independently and the cases where separating the CDSS impact was impossible were excluded.

Type of outcomes The included papers were evaluated for their outcomes related to the effect of CDSSs, which were categorized based on test-related, physician-related, and patient-related outcomes. These outcomes include: diagnostic yield and diagnostic detection rate, the number and cost of laboratory test ordered, laboratory turnaround time (TAT), STAT tests, guideline adherence for laboratory test ordering, physicians knowledge and attitude toward laboratory testing, patients outcome (e.g. patients safety, readmissions, death, length of stay and disposition). Test-related outcomes were the proportion of tests, cost of tests, test intervals, number of STAT request, and laboratory TATs. Physician-related outcomes include diagnostic yield and diagnostic detection rate, adherence or order cancellation after the reminders (or overriding the reminders), and physicians knowledge and attitude. Patient-related outcomes were patients' complications, patients' disposition, length of stay (LOS), and mortality rate.

\section{Exclusion criteria}

Exclusion criteria were studies published in any languages rather than English, conducted in outpatient or primary care settings, used as interventions rather than CDSS, conducted in an unreal clinical environment or based on a scenario (in a simulated setting i.e. to test a system). Moreover, all retrospective studies were excluded.

\section{Quality assessment}

The National Heart Lung and Blood Institute (NIH) quality assessment tools for each type of studies [25] were used to assess the methodological quality of the included studies. The variety of study designs necessitated the use of different NIH quality assessment tools, That is Quality Assessment of Controlled Intervention Studies, casecontrol studies, and before-after studies with no control group. NIH tool categorizes studies as good, fair, or poor. Included studies were independently assessed by two reviewers (SZ \& MS) and any disagreement over scoring was resolved by consensus.

Quality and features of the CDSSs were assessed using a checklist derived from Goldzweig et al. study [26]. This checklist considers the design and the degree of reporting information about CDSS and implementation characteristics. The checklist consists of three domains: CDSS design, data entry source, and implementation source.

\section{Data extraction}

A form was designed to extract data from each of the included studies. For each study the following data were extracted: study design, sample size, intervention description, and results. One author (SZ) extracted data which were subsequently reviewed and confirmed by another reviewer (EN).

\section{Data analysis}

A narrative synthesis was used to describe and compare the designs and the results of included studies. We categorized studies based on different features of CDSSs, outcome category, and effects of CDSSs. The effect of interventions were reported based on statistically significant positive, positive without statistical argument, no effect (not statistically significant), negative without statistical argument, or statistically significant negative [27]. Meta-analysis was not performed due to the variety of outcomes and results.

\section{Results}

\section{Study selection (Fig. 1)}

The literature search identified 2784 records, as well as two additional papers [28, 29] identified through other sources (snowball-search), 739 of which were duplicates. The papers were screened for eligibility by title and abstract, resulting in 74 potential papers for the full-text review. During the full-text reviewing, 58 papers were excluded. Finally, 16 studies were deemed eligible for inclusion.

\section{Characteristics of the included studies}

A substantial number of the included studies were performed during the recent decade. Overall, $81.2 \%$ of the included studies were published after 2010 and, of these, $69.2 \%$ were published after 2015. Most of the included studies were conducted in the United States $(n=12,75 \%)$; and one was conducted in each of the following countries: Canada [30], United Kingdom [31], Italy [32], and France [33] (Table 1). 


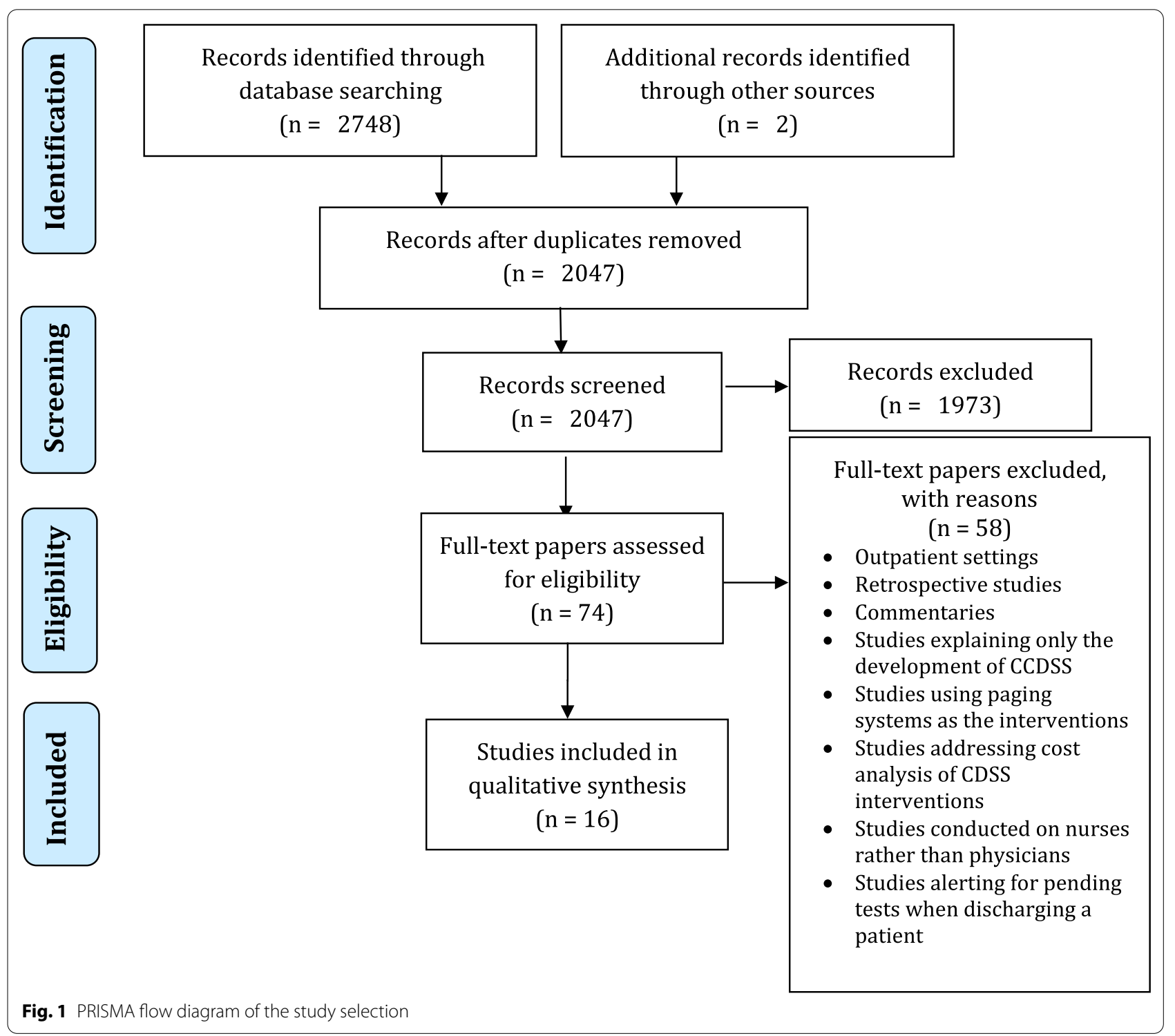

\section{Quality assessment (Table 2)}

One study was RCT [28], one case-control [39], and the others $(n=14)$ were quasi experimental studies (Additional file 2: supplementary B). Most of the included studies $(n=11,68.7 \%)$ were of intermediate quality, the remaining were of good quality. The main limitations of the included studies were not being blinded (93.7\% had not blinded assessors) and lack of a clear specified description of inclusion and exclusion criteria (43.7\%). The results are presented as a supplementary (Additional file 2: supplementary B).

The quality assessments of the CDSSs are presented in Table 2. Almost all CDSSs were integrated with CPOEs (93.7\%), providing real-time feedback (93.7\%) without any recommended action (100\%). Most CDSS classifications of the studies (43.7\%) are in C category which required the ordering clinician to justify why they were overriding the provided decision support recommendation (see Table 2 legend). Four studies (25\%) were integrated with and automated through EHR. Eight studies (50\%) reported that they had tested CDS before implementation. Only two studies (12.5\%) reported user training about the intervention; in other cases users were mostly trained about the indications required for ordering a specific test or similar things. Other characteristics, barriers, and facilitators affecting implementation of CDSS were: the role of order sets, "adjustment" period, stakeholder and champion leaders engagement, appropriate environment, ease of repeating targeted tests, 


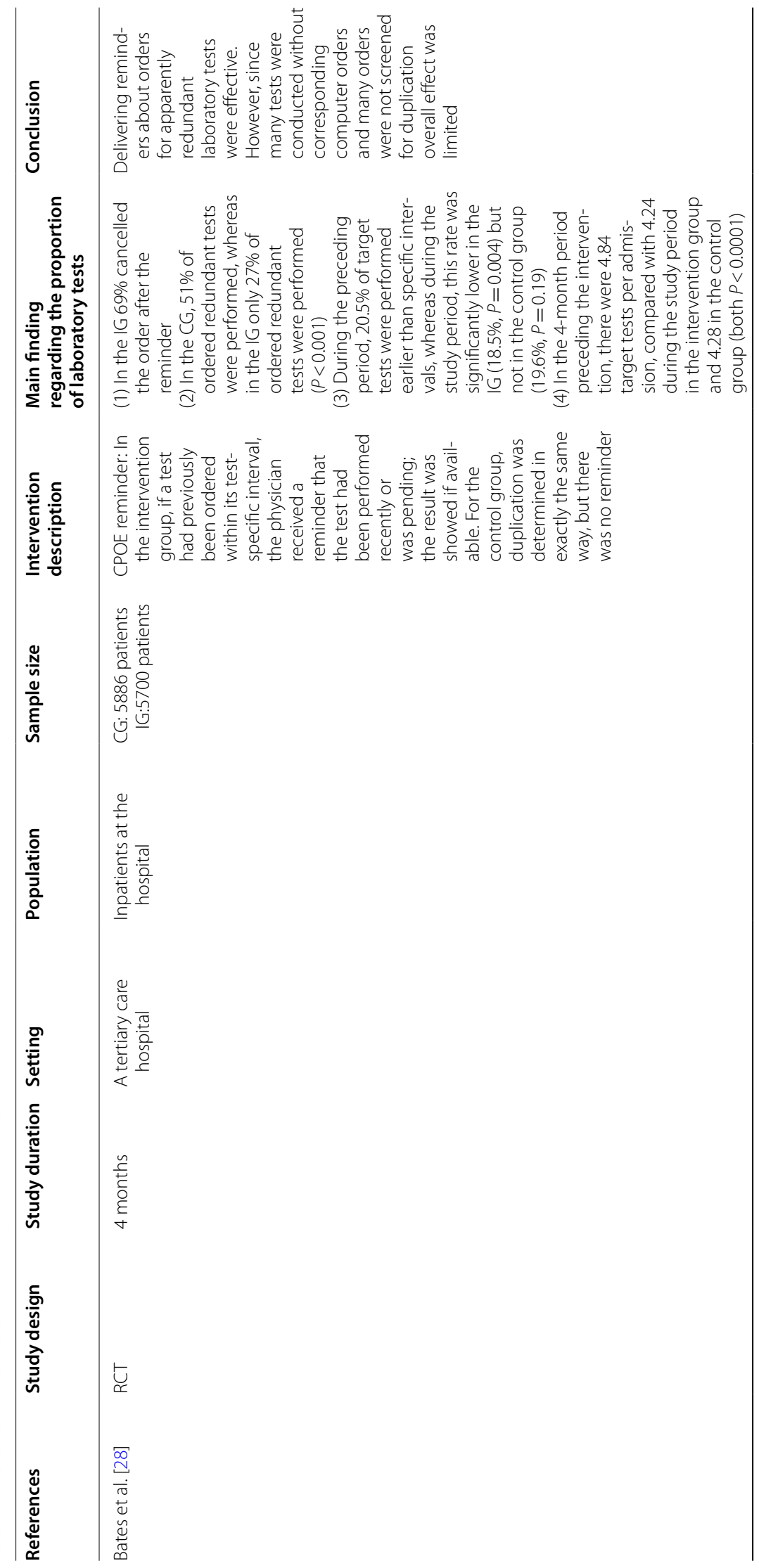




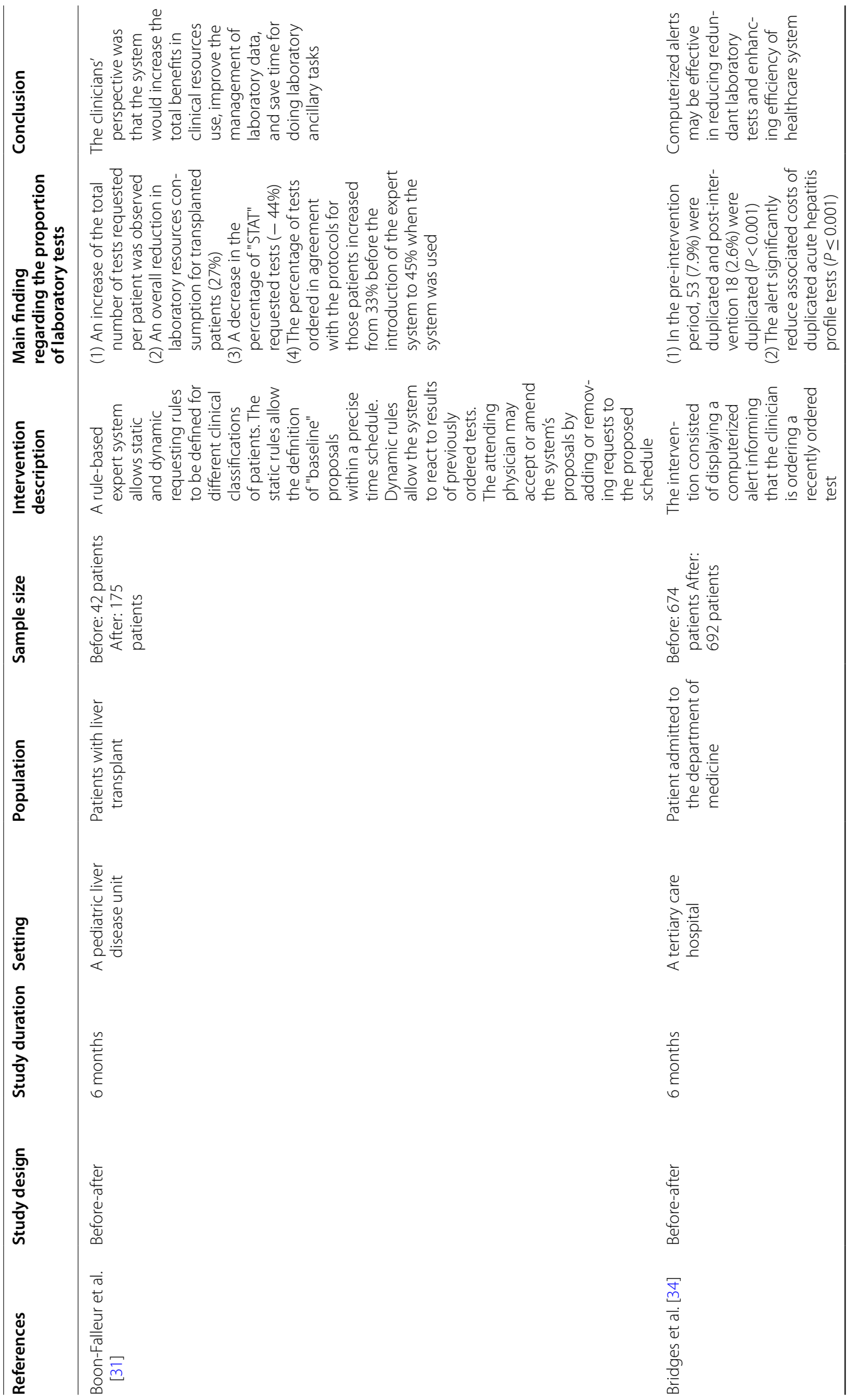




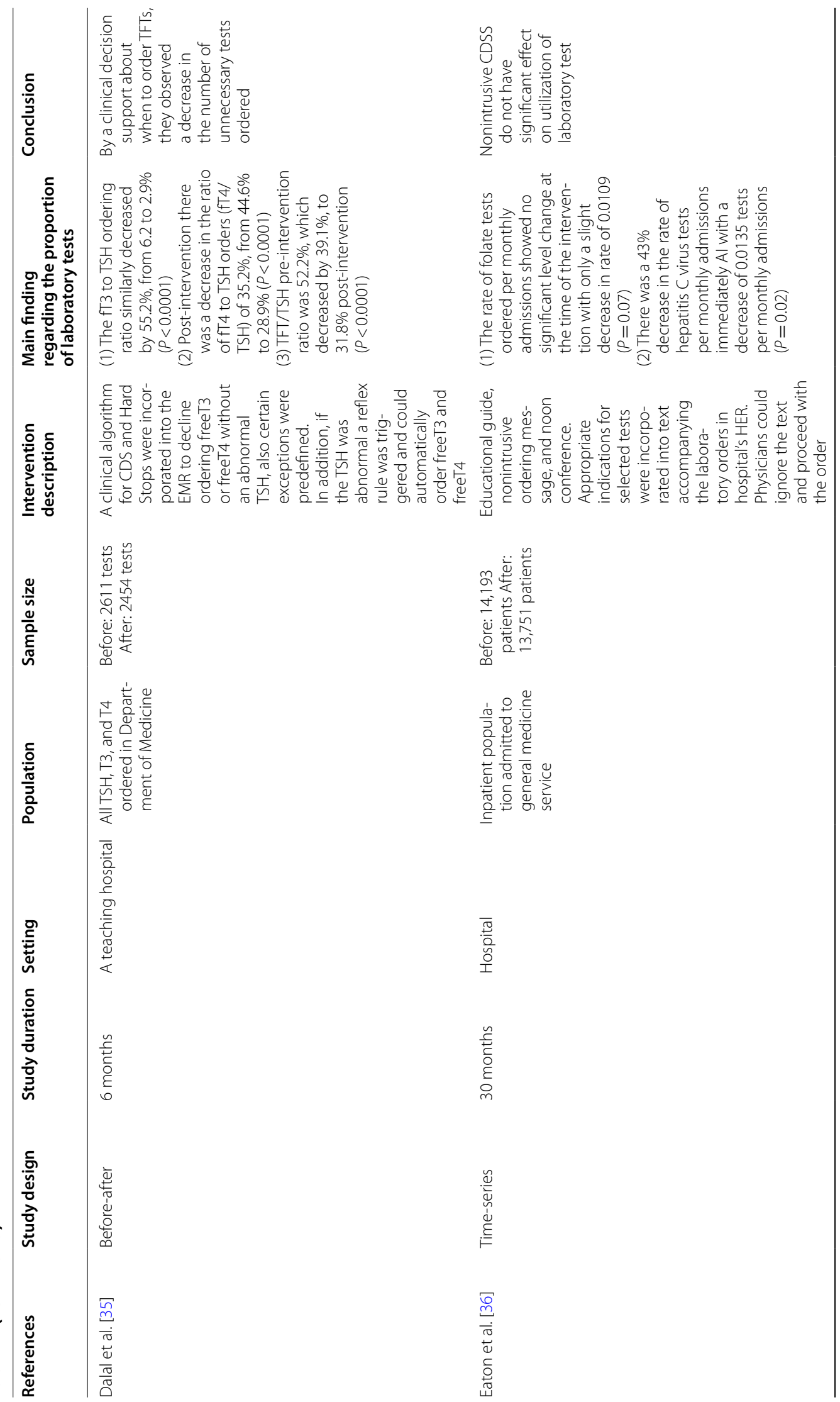




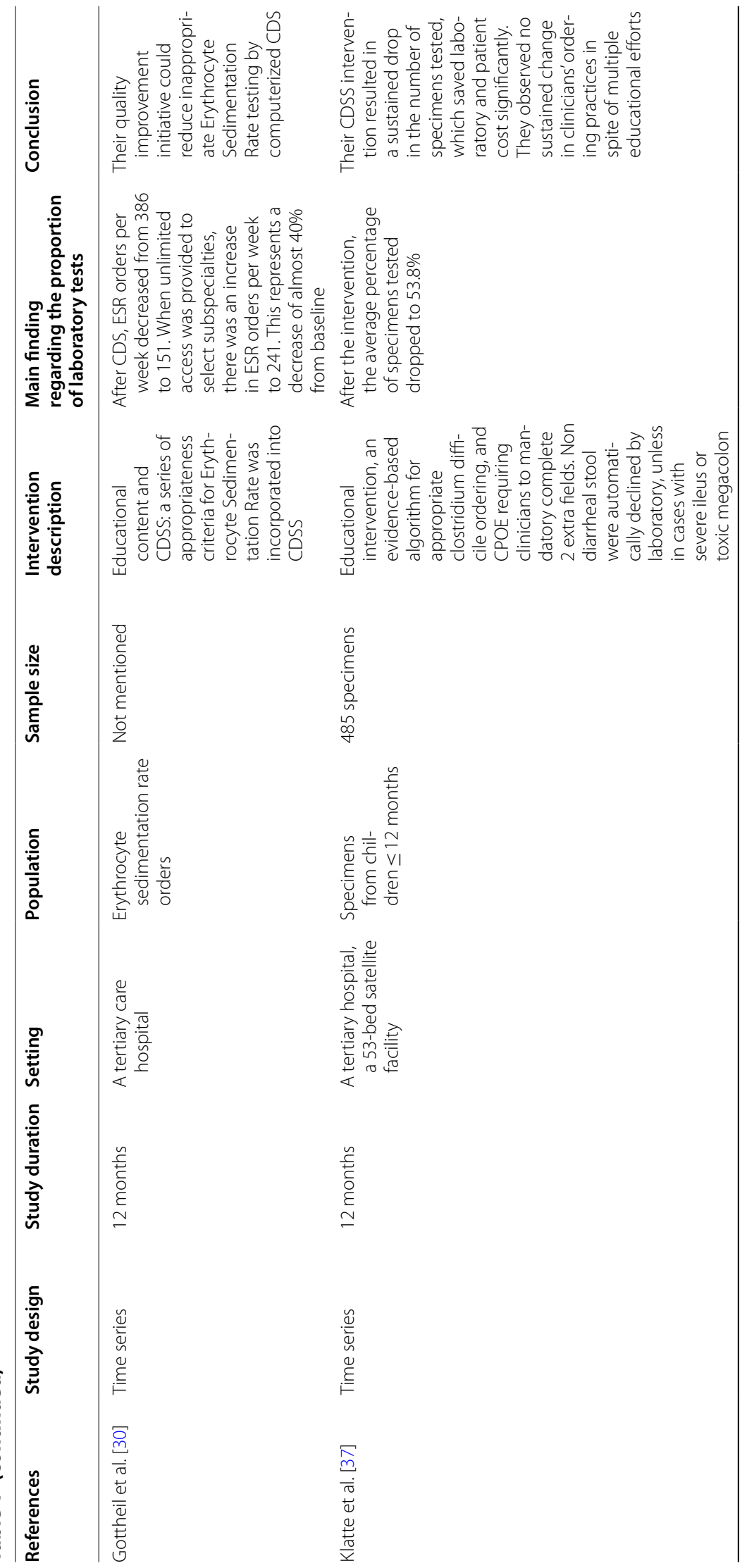




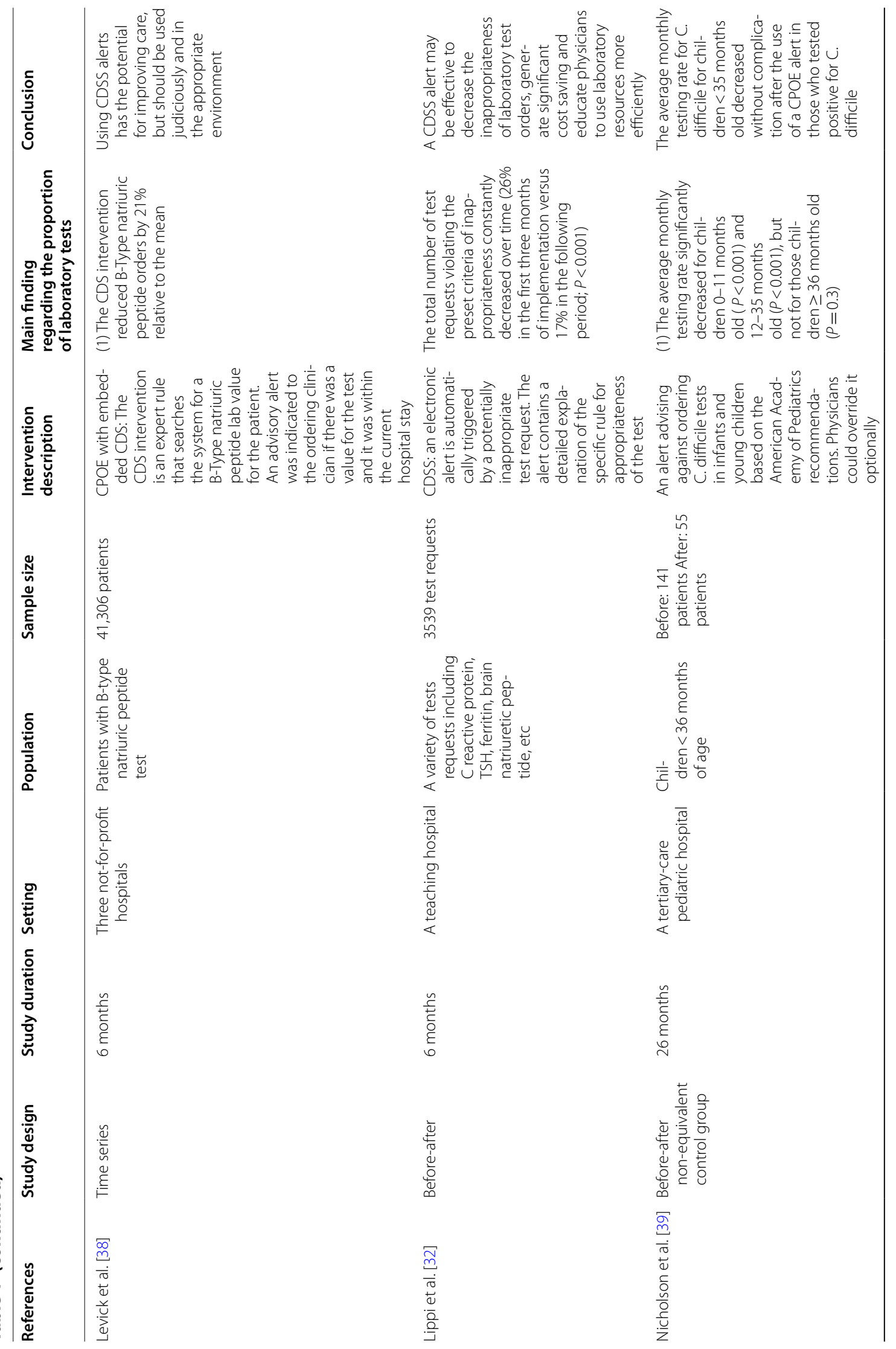




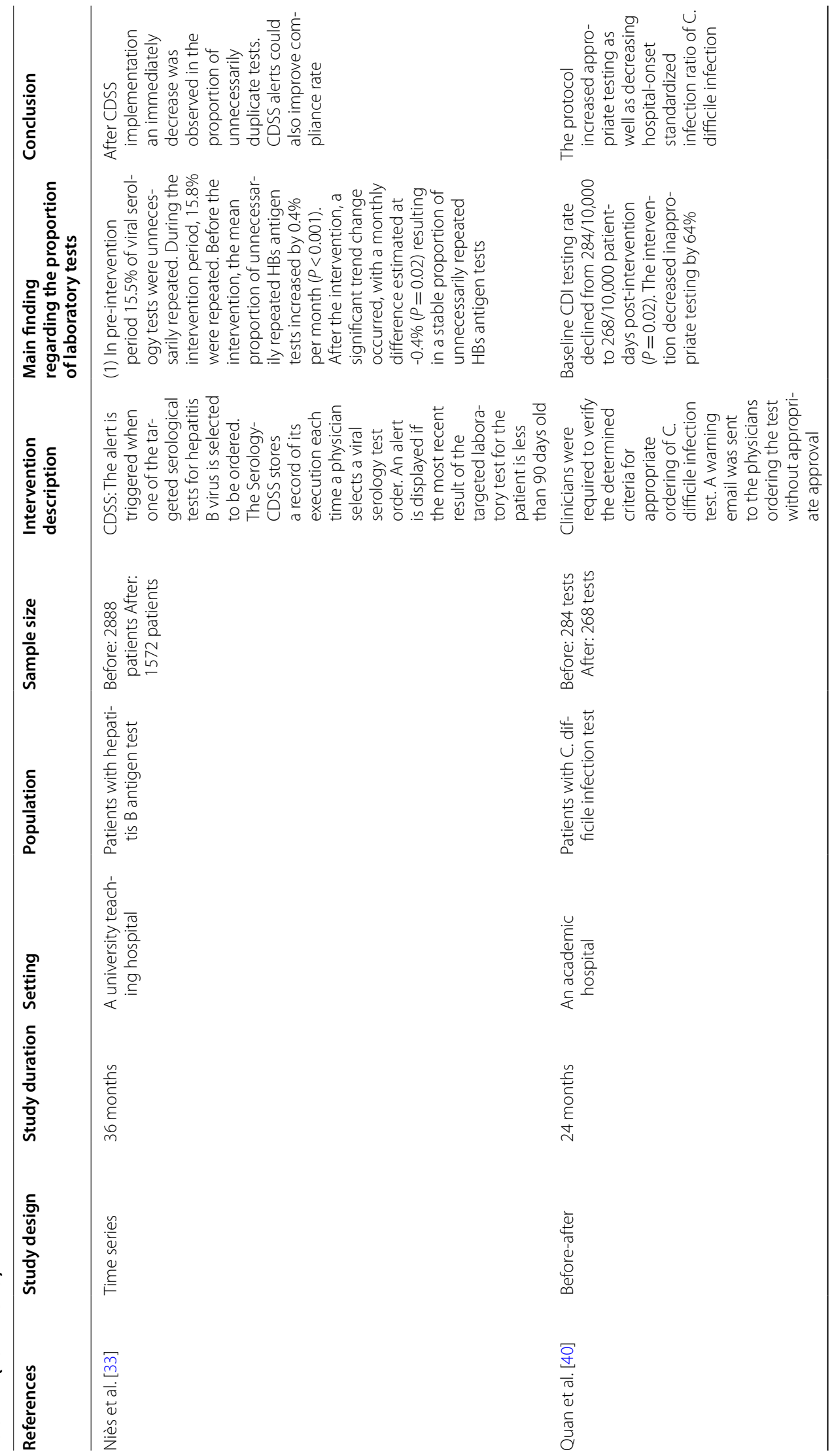




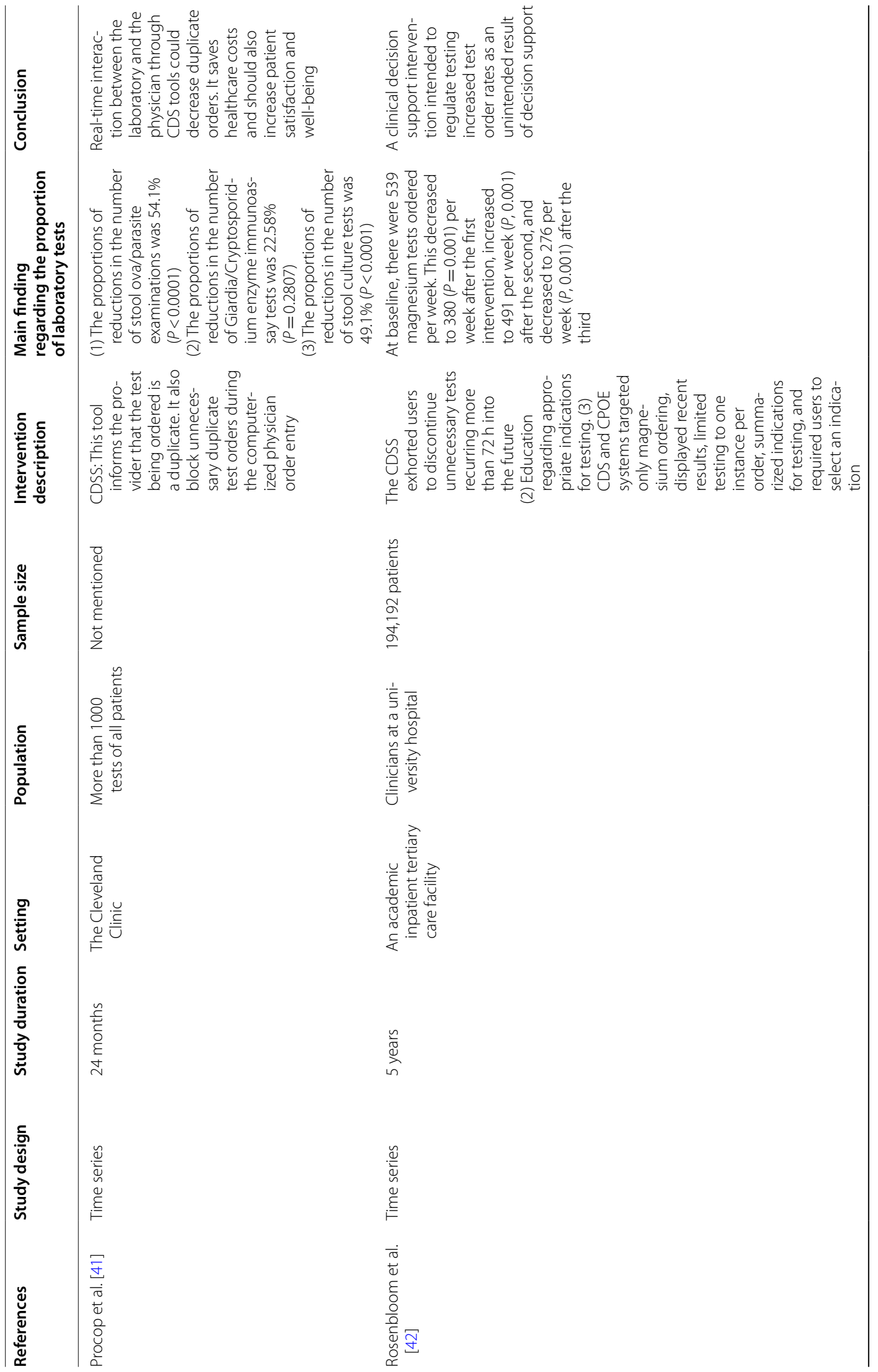




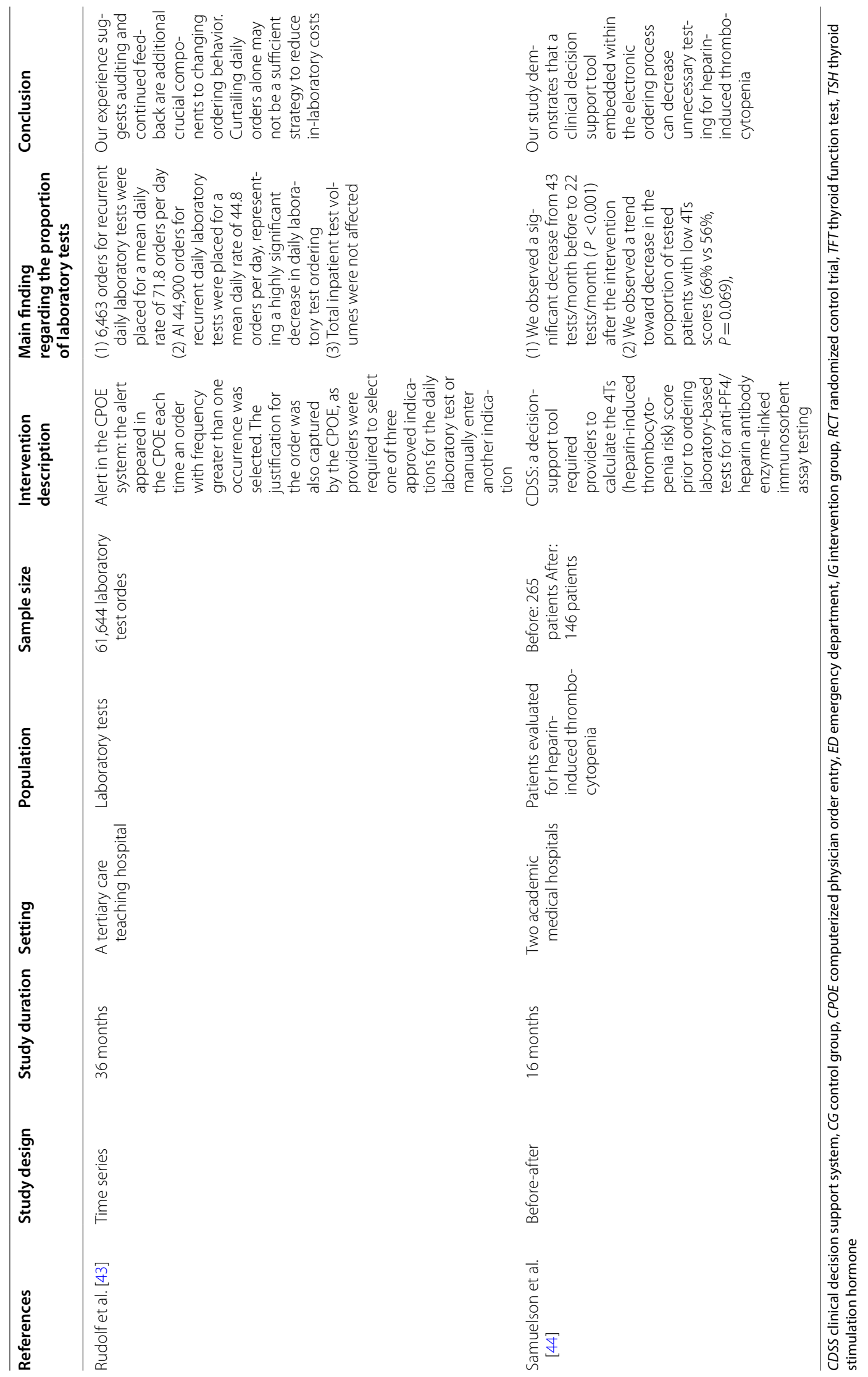




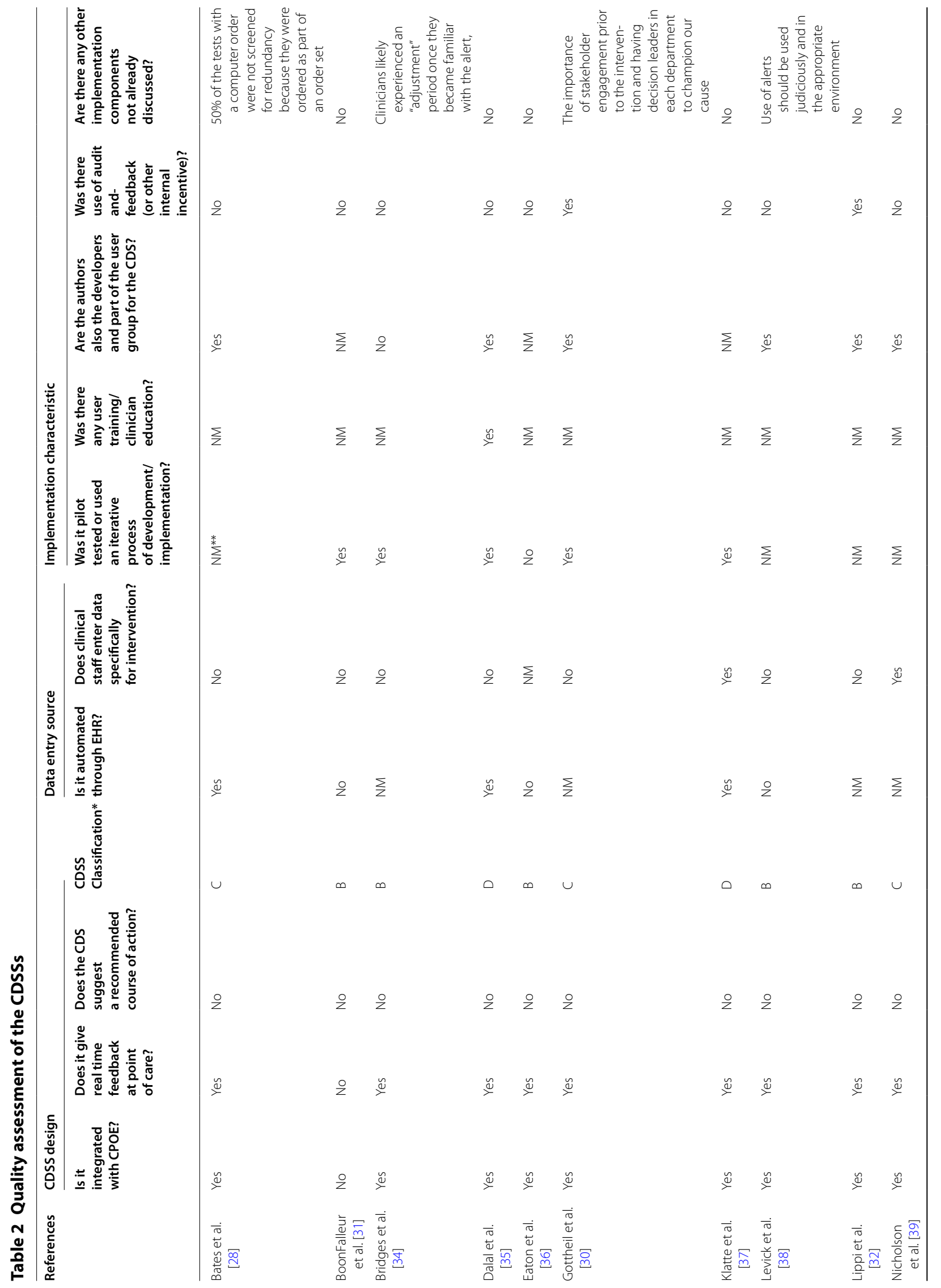




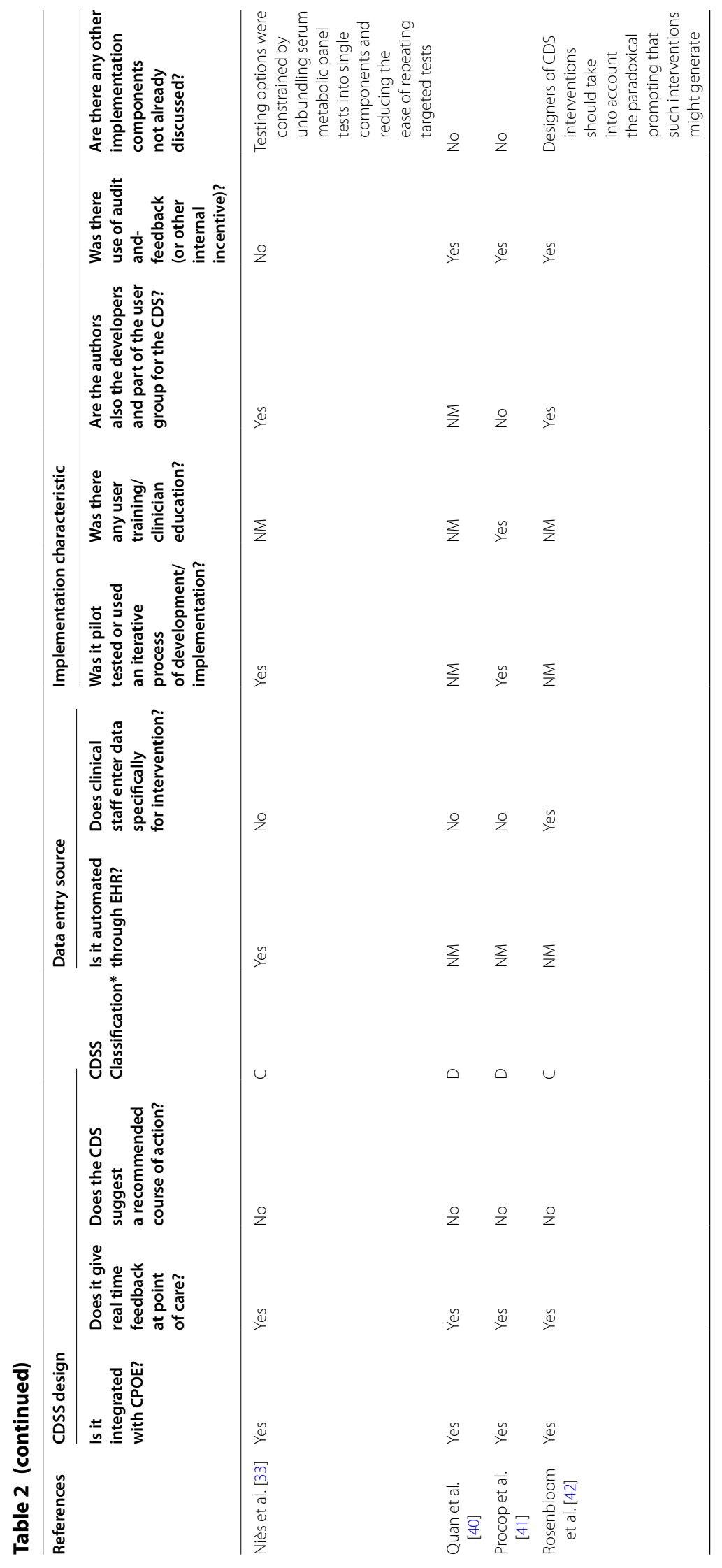




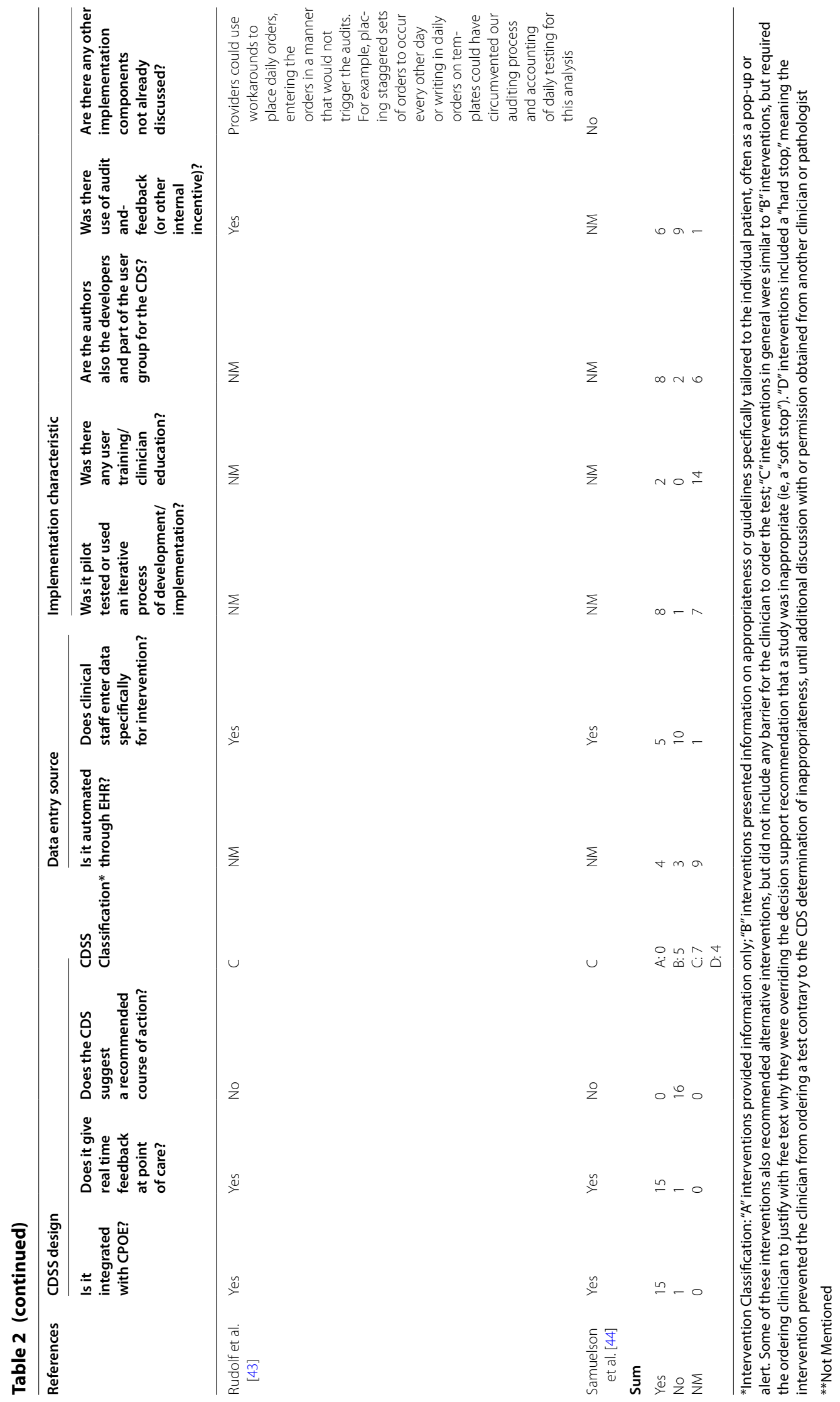


testing options constrains, paradoxical prompting generated by CDSS, and daily orders which would not trigger the audits.

CDSS interventions were mostly in the form of a reminder about duplicate tests in a specific timeframe, rule-bases providing knowledge about when it is appropriate to order the specified test, or predefined appropriateness criteria physicians had to determine before ordering the tests. These interventions support physicians' informed decision-making in the first step of testing process when they are deciding about ordering a test.

\section{Effects of CDSSs on outcomes (Table 3)}

The included studies had mostly investigated laboratory test-related outcomes. Generally, CDSS interventions showed positive effects on all outcomes.

\section{Laboratory test-related outcomes}

All the included studies have investigated the effects of CDSSs on proportion of laboratory tests. In general, studies showed positive impact on proportion of laboratory tests. The reported proportion of reduction varied from $21 \%$ [38] to 55\% [37] among the studies. The study by Boon-Falleur et al. [31], assessed as fair quality, applied a rule-based expert system for classified patients (Pre-transplant assessment, post-transplant assessment, and transplant monitoring) in liver transplant unit. The rule-based system increased laboratory utilization in pre-transplant assessment patients. The authors believed that, after the introduction of the system, physicians were asked to answer some precise questions, at patient admission, and it caused more often ordering of specialized diagnostic tests. However, it caused an overall reduction in laboratory resources consumption for transplanted patients. Eaton et al. [36] performed a multifaceted intervention in their good quality study indicating no effect on the rate of folate tests orders, but $43 \%$ reduction in the rate of hepatitis $\mathrm{C}$ virus tests. The study by Rudolf et al. [43] demonstrated that although recurrent daily laboratory tests reduced, the total tests volume remained unchanged. They stated that daily tests account for a small number of total tests; moreover, physicians may not decrease overall testing but instead shift testing to patients or conditions where it was more needed [43]. Rosenbloom et al. [42] used three CDSS interventions, two of which had a positive impact and one of which had a negative impact on magnesium ordering.

Cost of tests is also reported in half of the included studies. Results revealed that CDSSs had positive impact on reducing cost of tests. In most studies, except the one by Bridges et al. [34], with good quality, the reduction in the cost of laboratory tests was not analyzed with a statistical method [28, 30, 32, 37, 38, 41]. Test interval was only investigated in Bates et al., a good quality study [28], which showed a positive impact. "STAT" request of laboratory tests has only been investigated in a study by Boon-Falleur et al. [31] showing a positive impact.

\section{Physician-related outcomes}

Three studies reported the outcomes related to guideline adherence and all indicated positive impacts of CDSS. Compliance rate was measured based on the proportion of cancelled orders after the provision of the reminders or recommendations by CDSS. Boon-Falleur et al. [31] showed that $78 \%$ of the total performed laboratory tests were proposed by the static assessment protocols.

Table 3 Effects of CDSS interventions on laboratory testing outcomes

\begin{tabular}{|c|c|c|c|c|c|c|}
\hline \multicolumn{2}{|l|}{ Outcome } & \multicolumn{2}{|l|}{ Positive } & \multirow[t]{2}{*}{ No effect } & \multicolumn{2}{|l|}{ Negative } \\
\hline Category & Subcategory & $\begin{array}{l}\text { Statistically } \\
\text { significant }\end{array}$ & Demonstrated & & $\begin{array}{l}\text { Statistically } \\
\text { significant }\end{array}$ & Demonstrated \\
\hline \multirow[t]{4}{*}{ Test-related } & Proportion of tests & $\begin{array}{c}28,34,35,36 \\
32,39,33,40 \\
42^{*}, 44\end{array}$ & $31,36,30,37,38,41$ & $31,36,43$ & $42^{*}$ & \\
\hline & Cost of tests & 34 & $28,30,37,38,32,41$ & & & \\
\hline & Test intervals & 28 & & & & \\
\hline & Number of STAT request & & 31 & & & \\
\hline \multirow[t]{2}{*}{ Physician-related } & Guideline adherence & & 31,33 & & & \\
\hline & $\begin{array}{l}\text { Orders cancellation after the } \\
\text { reminders }\end{array}$ & & 28 & & & \\
\hline \multirow[t]{4}{*}{ Patient-related } & Patient complication & & & $28,39,41$ & & \\
\hline & Patient disposition & 34 & & & & \\
\hline & LOS & & & 34 & & \\
\hline & Mortality rate & 34 & & & & \\
\hline
\end{tabular}

*This study used three different CDSS intervention; two of which had positive impact and one of which had negative impact 
However, overall compliance to the dynamic protocols was $45 \%$. Actually the compliance to the static rules was more in comparison with the dynamic rules. Bates et al. [28] showed that $69 \%$ of the proportion of laboratory orders was canceled after the provision of alert. They also found that only $27 \%$ of ordered redundant tests were performed. In the study by Nies et al. [33] the compliance rate to the displayed alerts was $24 \%$. No outcome is reported regarding diagnostic detection rate and physicians' knowledge.

\section{Patient-related outcomes}

Patient-related outcomes were addressed in five studies. Cancellation of redundant tests based on the displayed alerts in some studies $[28,39,41]$ resulted in little or no loss of clinical information as well as no complication. Bridges et al. [34] showed that patients with duplicate tests had higher mortality rate than those without duplicate tests. They also had a worse disposition after discharge, indicating that those with redundant tests were generally sicker. Redundant tests are those which are performed before a defined time frame (interval) for repeating that test [28, 34, 41]. Duplicate tests are also defined as a test that is ordered after a previous test of the same type that is unlikely to change clinical plan [34]. In this study, the patients LOS also remained unchanged after the intervention.

\section{Discussion}

Generally, the studies were mostly of moderate methodological quality with only one RCT out of the 16 included studies as well as most studies being conducted after 2015. The majority of included studies were addressing the effect of CDSSs on laboratory test-related outcomes. The results showed improvement in laboratory testrelated and physician-related outcomes. Patient-related outcomes were not well investigated in the included studies.

Most studies conducted after 2015 suggested a new research agenda in health information technology. It also indicates that attentions to resource utilization for appropriate usage of laboratory tests have been increased recently. It might also be attributed to limited resources as well as increased cost of healthcare. Healthcare resource utilization and the costs by different diseases show a high economic burden highlighting need for taking some actions to decrease costs [45-47]. The results of this review showed that CDSSs have the ability to improve laboratory test utilization in some cases including hepatitis B virus, Clostridium Difficile, magnesium, B-Type natriuric peptide, TFT, ESR, and heparin-induced thrombocytopenia tests.

\section{Laboratory test-related outcomes}

Appropriate testing and cost saving were both affected by the CDSSs which is consistent with a similar systematic review on outpatient setting [22]. It is also consistent with a narrative review by Bindraban et al. [48] showing nearly all interventions in educational, CPOE, and audit and feedback category caused reduction in test order volume. Thesystematic review by Roshanov et al. [20] also indicated that those systems aiming at reducing test ordering rate had positive impact. However, the results are inconsistent with Delvaux and colleague systematic review. They found that CDSSs designed to change laboratory testing behavior for diabetes, HIV, and anticoagulation had little or no influence on clinical outcome. Our study included studies aiming at improving laboratory testing process as the primary aim. However, most studies included by Delvaux et al., as mentioned in introduction section, had different objective, for instance computer-aided dosing, and further evaluated its impact on diagnostic testing. Thus, it seems CDSSs specifically designed to affect laboratory tests are more influential. Eaton et al. [36] showed that CDSSs might be effective for some tests and ineffective for some others. There was only one study [42] that found a negative impact in magnesium ordering attributed to CDSS. The CDSS was supposed to regulate magnesium ordering; they developed a CDSS in a way that three tests (i.e. magnesium, calcium, and phosphorus) could be ordered from one user interface of CPOE. This may have caused an unintentional prompt to order these tests together without original plan. Cost reduction in laboratory tests was reported in several studies [28, 30, 32, 34, 37, 38, 41]. But it is important to mention that the quality of the studies was fair and the results were not analyzed statistically. Thus, the conclusion about cost reduction sounds difficult. However, it is stated that the reported cost reduction is an underestimation of true cost savings since they only assessed consumables costs; the associated resources (i.e. equipment, personnel, test tubes, etc.) should be included in the calculation.

\section{Physician-related outcomes}

The studies reporting physician-related outcomes $[28,31$, 33] showed positive effect on compliance to the CDSS recommendations. A systematic review by Delvaux et al. [23] also demonstrated a positive impact in compliance with recommendations made by CDSSs. Roshanov et al. [20] also concluded that CDSSs had positive impact on physicians' diagnostic test ordering behaviors. However, they believed that the contributing factors resulting in success or failure are unclear. Main et al. found 
that if they consider the result of both primary and secondary outcome then CDSSs is effective on physicians' behaviors.

\section{Patient-related outcomes}

The results also indicated that the evidence pertaining to the effects of CDSSs on patient-related outcomes is limited. Overall, CDSSs may make little or no difference to patient outcomes including patient complications, patient disposition, or mortality rate [28, 34, 39, 41]. For instance, in the study by Bates et al. [28], three of the eight urinalysis cancelled tests displayed a few red blood cells, while the previous specimen had been negative. It is inferred from these findings that cancelling the orders due to a CDSS suggestion, probably lead to no adverse event to patients. The study by Bridges et al. [34] showed that patients with duplicate tests had higher mortality rate than those without duplicate tests; they also had a worse disposition after discharge, indicating those with redundant tests were generally sicker. Thus, less mortality rate cannot be only attributed to CDSS effect and needs more investigation. Patient experience like decreased phlebotomy and other possible improved outcomes like decreased risk for false-positive test results should be investigated in future studies.

\section{Strengths and limitations}

A comprehensive search strategy, without any time period restriction, was performed to find the maximum number of relevant studies. To avoid missing any important findings, a variety of interventional study designs were included. We assessed the effects of CDSSs not only on proportion of test orders and associated costs but also on physician-related and patient-related clinical outcomes.

A limitation of this review is that due to exclusion of non-English language papers and conference proceedings, some relevant studies might have been missed. Another limitation is the exclusive focus on studies on reducing unnecessary testing as the main outcome. Most studies conducted in this field were performed using a quasi-experimental design making the conclusion about the impacts difficult due to possible biases.

\section{Implication}

Applying a clinical algorithm and hard stop alerts for preventing specified tests would result in more reduction in tests volume. CDSSs should be evaluated for specific laboratory tests to make sure only effective alerts would be displayed [36]. Nonetheless, allowing overrides may be effective for clinicians' acceptance of the system. Nonintrusive alerts should be evaluated to make sure only effective alerts continue to be displayed so as to prevent rising alert fatigue [36]. Alert fatigue causes both important and non-important alerts to be overridden by clinicians. Thus, considering a balance between system flexibility and hard-stop alerts is important in designing a CDSS. It is suggested that the intervention must be sustainable through providing awareness to the changes, which will bring about better compliance. Impact on physician-related outcomes can be promoted over time, since physicians possibly experience an "adjustment" period at the beginning of the intervention; therefore, they need time to become familiar with the intervention [34]. Although physicians' attitude and requirements are important factors contributing in more acceptances and perceived usefulness of CDSS, less attention has been paid to them. It has been shown that simple static rules had higher compliance rates than complicated dynamic rules [31]. CDSSs design should not allow two or more tests to be ordered from a single interface, because it may contribute in unintentional prompt to order those tests together and increase tests ordering.

\section{Future research directions}

Since most studies were conducted after 2015, indicating a new research agenda, there is a need for more studies investigating effective information technologybased approaches to manage health resources utilization. Moreover, considering the majority of the studies were performed using a quasi-experimental design, there is an essential need for further studies with more robust study designs. Also, to make sure about the effects of CDSSs on test interval, STAT tests, and TAT, further studies are needed. Considering lack of evidence on potential negative effects resulting from the cancellation of the tests based on CDSS recommendations, future research should evaluate these effects, especially potential harm to patients. Although some physicians need guidance when interpreting some tests $[49,50]$ and CDSSs have the potential to aid them, according to our review there was no physician aid for interpreting the result; new research can investigate the effects of CDSSs as a physician aid for interpreting the laboratory tests results.

\section{Conclusion}

Current systematic review indicate that CDSSs increase appropriate test ordering through eliminating redundant test orders and enhancing evidence-based practice in hospitals. The literatures showed that CDSSs have the potential to influence on cost savings. However, evidence is limited about the impact of cancelling order tests on patient health and needs further studies. As suggested, there is an essential need for further studies with more robust study designs like randomized controlled trials. 


\section{Supplementary Information}

The online version contains supplementary material available at https://doi. org/10.1186/s12911-020-01384-8.

Additional file 1. Search strategy.

Additional file 2. Quality assessment of the included studies.

\section{Abbreviations}

CDSS: Clinical decision support system; EMR: Electronic medical record; EHR: Electronic health record; CPOE: Computerized physician order entry; TAT: Turnaround time; RCT: Randomized controlled trials; CCT: Controlled clinical trials; ITS: Interrupted time series; ED: Emergency department; IG: Intervention group; CG: Control group; TFT: Thyroid function test; TSH: Thyroid stimulation hormone; C. difficile: Clostridium difficile.

\section{Acknowledgements}

No acknowledgement.

\section{Authors' contributions}

EN and ZM supervised the study. SZ MS contributed in reading the articles for relevance and disagreements were solved by EN. SZ extracted the information of the included studies. SZ and EN have drafted the manuscript. All authors read and approved the final manuscript.

\section{Funding}

No funding is received for this research.

\section{Availability of data and materials}

All data are available in the submission.

\section{Ethics approval and consent to participate}

The study is approved by the ethics review board of the Vice-chancellor for Research Affairs of KaUMS (IR.KAUMS.NUHEPM.REC.1398.005). Consent to participate is not applicable.

\section{Consent for publication}

Not applicable.

\section{Competing interests}

The authors declare that there are no conflicts of interest

\section{Author details}

${ }^{1}$ Health Information Management Research Center (HIMRC), 5th of Qotb -e Ravandi Blvd, Kashan University of Medical Science, 87159-73449 Kashan, Iran.

${ }^{2}$ Department of Health Information Management and Technology, Kashan University of Medical Sciences, Kashan, Iran. ${ }^{3}$ Health Information Management, Human Resources Development Research Center, Shiraz University of Medical Sciences, Shiraz, Iran.

Received: 20 July 2020 Accepted: 25 December 2020

Published online: 18 January 2021

\section{References}

1. Zhi M, Ding EL, Theisen-Toupal J, Whelan J, Arnaout R. The landscape of inappropriate laboratory testing: a 15-year meta-analysis. PLoS ONE. 2013;8(11):e78962.

2. Stilwell JA, Young D, Cunnington A. Evaluation of laboratory tests in hospitals. Ann Clin Biochem. 1980;17(6):281-6.

3. Nachamkin I. How many lab tests do patients really need? University of Pennsylvania. Pathology and Laboratory Medicine; 2015. http://patho logy.med.upenn.edu/department/blogs/pepper-talk/how-many-labtests-do-patients-really-need.

4. Naugler C, Ma I. More than half of abnormal results from laboratory tests ordered by family physicians could be false-positive. Can Fam Phys. 2018;64(3):202-3.
5. Thavendiranathan P, Bagai A, Ebidia A, Detsky AS, Choudhry NK. Do blood tests cause anemia in hospitalized patients? The effect of diagnostic phlebotomy on hemoglobin and hematocrit levels. J Gen Intern Med. 2005;20(6):520-4.

6. Kachalia A, Gandhi TK, Puopolo AL, Yoon C, Thomas EJ, Griffey R, et al. Missed and delayed diagnoses in the emergency department: a study of closed malpractice claims from 4 liability insurers. Ann Emerg Med. 2007:49(2):196-205

7. Gandhi TK, Kachalia A, Thomas EJ, Puopolo AL, Yoon C, Brennan TA, et al. Missed and delayed diagnoses in the ambulatory setting: a study of closed malpractice claims. Ann Intern Med. 2006;145(7):488-96.

8. Medicine NAo. Improving diagnosis in health care. Washington: National Academies Press; 2015.

9. Holland LL, Smith LL, Blick KE. Reducing laboratory turnaround time outliers can reduce emergency department patient length of stay: an 11-hospital study. Am J Clin Pathol. 2005;124(5):672-4.

10. Meidani Z, Farzandipour M, Hosseinpour M, Kheirkhah D, Shekarchi M, Rafiei S. Evaluating inappropriate patient stay and its reasons based on the appropriateness evaluation protocol. Nurs Midwifery Stud. 2017:6(3):121-4.

11. Rogg JG, Rubin JT, Hansen P, Liu SW. The frequency and cost of redundant laboratory testing for transferred ED patients. Am J Emerg Med. 2013;7(13):1121-3.

12. Naugler C, Thomas R, Turin TC, Guo M, Vaska M. Yearly clinical laboratory test expenditures for different medical specialties in a major Canadian city. Am J Clin Pathol. 2015;144(1):97-102.

13. Meidani Z, Farzandipour M, Farrokhian A, Haghighat M. A review on laboratory tests' utilization: a trigger for cutting costs and quality improvement in health care settings. Med J Islam Repub Iran. 2016:30:365.

14. Blaya JA, Shin SS, Yagui M, Contreras C, Cegielski P, Yale G, et al. Reducing communication delays and improving quality of care with a tuberculosis laboratory information system in resource poor environments: a cluster randomized controlled trial. PLoS ONE. 2014;9(4):e90110.

15. Bell DS, Cima L, Seiden DS, Nakazono TT, Alcouloumre MS, Cunningham WE. Effects of laboratory data exchange in the care of patients with HIV. Int J Med Inform. 2012;81(10):e74-82.

16. Turner HE, Deans KA, Kite A, Croal BL. The effect of electronic ordering on pre-analytical errors in primary care. Ann Clin Biochem. 2013;50(Pt 5):485-8.

17. Georgiou A, Lang S, Rosenfeld D, Westbrook Jl. The use of computerized provider order entry to improve the effectiveness and efficiency of coagulation testing. Arch Pathol Lab Med. 2011:135(4):495-8.

18. Hunt D, Haynes R, Hanna S, et al. Effects of computer-based clinical decision support systems on physician performance and patient outcomes. JAMA. 1998;280:1339.

19. Revolinsk S. Implementation of a clinical decision support alert for the management of Clostridium difficile infection. Antibiotics (Basel). 2015;4:667-74

20. Roshanov PS, You JJ, Dhaliwal J, Koff D, Mackay JA, Weise-Kelly L, et al. Can computerized clinical decision support systems improve practitioners' diagnostic test ordering behavior? A decision-maker-researcher partnership systematic review. Implement Sci. 2011;6:88.

21. Main C, Moxham T, Wyatt JC, Kay J, Anderson R, Stein K. Computerised decision support systems in order communication for diagnostic, screening or monitoring test ordering: systematic reviews of the effects and cost-effectiveness of systems. Health Technol Assess. 2010;14(48):1-227.

22. Maillet E, Pare G, Currie LM, Raymond L, Ortiz de Guinea A, Trudel MC, et al. Laboratory testing in primary care: a systematic review of health IT impacts. Int J Med Inform. 2018;116:52-69.

23. Delvaux N, Van Thienen K, Heselmans A, de Velde SV, Ramaekers D, Aertgeerts, . The effects of computerized clinical decision support systems on laboratory test ordering: a systematic review. Arch Path Lab Med. 2017;141(4):585-95.

24. Payne TH. Computer decision support systems. Chest. 2000;118(2):47S-52S.

25. Institute TNHLaB Quality assessment tool. https://www.nhlbi.nih.gov/ health-topics/study-quality-assessment-tools.

26. Goldzweig CL, Orshansky G, Paige NM, Ewing BA, Miake-Lye IM, Beroes $J M$, et al. VA evidence-based synthesis program reports. Electronic health record-based interventions for reducing inappropriate imaging in the 
clinical setting: a systematic review of the evidence. Washington: Department of Veterans Affairs (US); 2015.

27. Nabovati E, Vakili-Arki H, Taherzadeh Z, Saberi MR, Medlock S, Abu-Hanna $A$, et al. Information technology-based interventions to improve drugdrug interaction outcomes: a systematic review on features and effects. J Med Syst. 2017;41(1):12.

28. Bates DW, Kuperman GJ, Rittenberg E, Teich JM, Fiskio J, Ma'luf N, et al. A randomized trial of a computer-based intervention to reduce utilization of redundant laboratory tests. Am J Med. 1999:106(2):144-50.

29. Waldron JL, Ford C, Dobie D, Danks G, Humphrey R, Rolli A, et al. An automated minimum retest interval rejection rule reduces repeat CRP workload and expenditure, and influences clinician-requesting behaviour. J Clin Pathol. 2014;67(8):731-3.

30. Gottheil S, Khemani E, Copley K, Keeney M, Kinney J, Chin-Yee I, et al. Reducing inappropriate ESR testing with computerized clinical decision support. BMJ Qual Improv Rep. 2016;5(1): u211376-w4582.

31. Boon-Falleur L, Sokal E, Peters M, Ketelslegers JM. A rule-based decision support application for laboratory investigations management. In: Proceedings symposium on computer applications in medical care; 1995. p. 314-318.

32. Lippi G, Brambilla M, Bonelli P, Aloe R, Balestrino A, Nardelli A, et al. Effectiveness of a computerized alert system based on re-testing intervals for limiting the inappropriateness of laboratory test requests. Clin Biochem. 2015:48(16-17):1174-6.

33. Nies J, Colombet I, Zapletal E, Gillaizeau F, Chevalier P, Durieux P. Effects of automated alerts on unnecessarily repeated serology tests in a cardiovascular surgery department: a time series analysis. BMC Health Serv Res. 2010;10:70

34. Bridges SA, Papa L, Norris AE, Chase SK. Duplicated laboratory tests: evaluation of a computerized alert intervention abstract. J Healthc Qual. 2014:36(3):46-53.

35. Dalal S, Bhesania S, Silber S, Mehta P. Use of electronic clinical decision support and hard stops to decrease unnecessary thyroid function testing. BMJ Qual Improv Rep. 2017;6(1):u223041.w8346.

36. Eaton KP, Chida N, Apfel A, Feldman L, Greenbaum A, Tuddenham $\mathrm{S}$, et al. Impact of nonintrusive clinical decision support systems on laboratory test utilization in a large academic centre. J Eval Clin Pract. 2018:24(3):474-9.

37. Klatte JM, Selvarangan R, Jackson MA, Myers AL. Reducing overutilization of testing for clostridium difficile infection in a pediatric hospital system: a quality improvement initiative. Hosp Pediatr. 2016;6(1):9-14.

38. Levick DL, Stern G, Meyerhoefer CD, Levick A, Pucklavage D. Reducing unnecessary testing in a CPOE system through implementation of a targeted CDS intervention. BMC Med Inform Decis Mak. 2013;13:43.

39. Nicholson MR, Freswick PN, Di Pentima MC, Wang L, Edwards KM, Wilson $\mathrm{GJ}$, et al. The use of a computerized provider order entry alert to decrease rates of clostridium difficile testing in young pediatric patients. Infect Control Hosp Epidemiol. 2017;38(5):542-6.
40. Quan KA, Yim J, Merrill D, Khusbu U, Madey K, Dickey L, et al. Reductions in clostridium difficile infection (CDI) rates using real-time automated clinical criteria verification to enforce appropriate testing. Infect Control Hosp Epidemiol. 2018;39(5):625-7.

41. Procop GW, Yerian LM, Wyllie R, Harrison AM, Kottke-Marchant K. Duplicate laboratory test reduction using a clinical decision support tool. Am J Clin Pathol. 2014;141(5):718-23.

42. Rosenbloom ST, Chiu KW, Byrne DW, Talbert DA, Neilson EG, Miller RA. Interventions to regulate ordering of serum magnesium levels: report of an unintended consequence of decision support. JAMIA. 2015;12(5):546-53.

43. Rudolf JW, Dighe AS, Coley CM, Kamis IK, Wertheim BM, Wright DE, et al. Analysis of daily laboratory orders at a large urban academic center: a multifaceted approach to changing test ordering patterns. Am J Clin Pathol. 2017;148(2):128-35.

44. Samuelson BT, Glynn E, Holmes M, White AA, Martin DB, Garcia D. Use of a computer-based provider order entry (CPOE) intervention to optimize laboratory testing in patients with suspected heparin-induced thrombocytopenia. Thromb Res. 2015;136(5):928-31.

45. Murata K, Hinotsu S, Sadamasa N, Yoshida K, Yamagata S, Asari S, et al. Healthcare resource utilization and clinical outcomes associated with acute care and inpatient rehabilitation of stroke patients in Japan. Int J Qual Health Care. 2017;29(1):26-31.

46. Nguyen MH, Burak Ozbay A, Liou I, Meyer N, Gordon SC, Dusheiko G, et al. Healthcare resource utilization and costs by disease severity in an insured national sample of US patients with chronic hepatitis B. J Hepatol. 2019;70(1):24-32.

47. Chen K, Krasner A, Li N, Xiang CQ, Totev T, Xie J. Clinical burden and healthcare resource utilization among patients with chronic hypoparathyroidism, overall and by adequately vs not adequately controlled disease: a multi-country chart review. J Med Econ. 2019;22(11):1141-52.

48. Bindraban R, Berg M, Naaktgeboren C, et al. Reducing test utilization in hospital settings: a narrative review. Ann Lab Med. 2018;38:402-12.

49. McGlynn EA, Asch SM, Adams J, Keesey J, Hicks J, DeCristofaro A, et al. The quality of health care delivered to adults in the United States. N Engl J Med. 2003;348(26):2635-45.

50. Schmidt RL, Garcia CA, Panlener J, Ashwood ER, Jackson BR, Hussong JW. An analysis of clinical consultation activities in clinical chemistry: implications for transformation and resident training in chemical pathology. Arch Pathol Lab Med. 2014;138(5):671-7.

\section{Publisher's Note}

Springer Nature remains neutral with regard to jurisdictional claims in published maps and institutional affiliations.

Ready to submit your research? Choose BMC and benefit from:

- fast, convenient online submission

- thorough peer review by experienced researchers in your field

- rapid publication on acceptance

- support for research data, including large and complex data types

- gold Open Access which fosters wider collaboration and increased citations

- maximum visibility for your research: over $100 \mathrm{M}$ website views per year

At BMC, research is always in progress.

Learn more biomedcentral.com/submissions 